\title{
COVID-19 pandemic and the protection of workers' health from disinfectant chemicals
}

\author{
Kyung-Taek $\operatorname{Rim}^{1}$ (C)
}

Accepted: 16 December 2020 / Published online: 7 January 2021

(c) Korean Society of Environmental Risk Assessment and Health Science 2021

\begin{abstract}
Objective and methods This study examines the protection of workers from the "COVID-19" pandemic, especially healthcare workers, disinfection workers, and future prospects in occupational health. To summarize this concept, I searched the major websites using the key terms "COVID-19," "coronavirus," "pandemic," "workers' health," and "quarantine" or "disinfection." Results and conclusion The use of disinfectants is recognized to be effective in preventing viruses, but this is also increasing the need to solve problems, such as the side effects caused by the increase in disinfectant use. This paper presents the precautions for safer use of chemicals handled by workers during quarantine and disinfection and proposes policy suggestions. The COVID-19 pandemic will have long-lasting effects on workers. Syndromic methods for monitoring illness outside of healthcare settings can be useful adjuncts to conventional disease reporting. From these results, it is important that the precautions for chemicals' safety handled by workers during quarantine and disinfection as well as policy suggestions for quarantine and disinfection workers are very important to protect workers.
\end{abstract}

Keywords COVID-19 $\cdot$ Pandemic $\cdot$ Protect $\cdot$ Review $\cdot$ Workers' health

\section{Introduction}

The novel coronavirus infection (hereinafter referred to as COVID-19) is a prevalent concern worldwide. As a guideline for personal hygiene to prevent the spread of the virus, it is recommended to wash hands with soap for at least $30 \mathrm{~s}$, or use hand sanitizers. Viruses are mainly transmitted through droplets in close contact between humans and sputum from infected humans, or contaminated substances, such as sputum, or contact infections, so quarantine and disinfection are very important. In this situation, a family member, while spraying a dilute methanol solution with a nebulizer to disinfect the house, complained of abdominal pain, vomiting, and dizziness, and visited the hospital emergency room. The cause of these cases of misuse is that high concentrations of methanol vapor remain indoors with poor ventilation, without subjects knowing the harmfulness of the chemicals [1]. Methanol is a toxic substance that irritates the eyes and

Kyung-Taek Rim

rim3249@gmail.com

1 Chemicals Research Bureau, Occupational Safety and Health Research Institute, Korea Occupational Safety and Health Agency, Daejeon, Korea respiratory tract, and when exposed for a long period of time, or repeated, causes damage to the central nervous system and optic nerves. The Korea Safety and Health Agency (KOSHA) advises through the website and SNS not to disinfect using methanol at workplaces and homes [2]. The COVID-19 pandemic is rapidly presenting serious practical clinical challenges for workers to healthcare administrators and policy formulators [3]. Since COVID-19 is spreading rapidly around the world with devastating consequences for healthcare workers, health systems, and economies, global efforts will be required to support faltering economies and healthcare systems [4].

This report examines the effects of the COVID-19 pandemic on workers, especially healthcare workers, and disinfection workers, and on future prospects in occupational health. This report summarizes a literature review I undertook by searching the major websites used in most reviews for the necessary data, specifically Google Scholar (http:// scholar.google.com), ScienceDirect (www.sciencedirect. com), Scopus (www.scopus.com), NDSL (http://www. ndsl.kr/index.do), and PubMed (http://www.ncbi.nlm.nih. gov/pubmed). The search was performed using the key terms "COVID-19," "coronavirus," "pandemic," "workers' health," and "quarantine" or "disinfect." To accomplish the 
purpose of this research, only necessary data were selected from the searched data, and it was then summarized into the following categories: "COVID-19 and quarantine or disinfection," "Chemical safety and health of quarantine/disinfection," "Toxicity and occupational safety and health issues of quarantine/disinfection," and "Requirements for worker safety in quarantine/disinfection." Based on these summaries, measures for worker safety and the future direction of the quarantine/disinfection works for COVID-19 pandemic were discussed.

\section{COVID-19 and workers}

Sars-CoV-2 pandemic has affected all aspects of global civilization, including the entire working sector. While the COVID-19 virus overlays existing health disparities among farmworkers, the population is not homogenous. More research is needed into the health and safety needs of workers [5]. Many countries have shown a good response to the SARS-CoV-2 emergency [6].

In Iran, there was a case of death by drinking methanol to eliminate COVID-19. Some local governments used drones to spray disinfectants to prevent the spread of COVID-19, but the main component of the disinfectant was known as benzalkonium chloride (BKC). Methanol is a chemical substance that caused death by acute poisoning during the work of mobile phone parts in 2016, and benzalkonium chloride is one of the humidifier disinfectant substances that caused social disaster. There have also been incidents in which chemical substances used for effective quarantine and disinfection have adversely affected public health [7-9]. In addition to health care for the pandemic, psychological support should be provided to workers, and their working conditions should be improved [10].

\section{COVID-19 and workers with quarantine or disinfection}

Due to the recent spread of COVID-19, the demand for disinfectants for quarantine and disinfection has increased. As exaggerated advertisements are increasing in number, the government is providing accurate information by releasing a list of approved related products. The Ministry of Environment (MoE) recommends disinfectants to sterilize COVID-19 that have received notification or the approval of the MoE, in order to prevent damage [11]. A list of disinfectant products and detailed guidelines for safe use have been prepared. Among them, sodium hypochlorite is a substance that is mainly used for commonly used lactose and fungicides. Table 1 shows EPA's list of products for use against SARS-CoV-2 and their toxicological data. All products on this list meet EPA's criteria for use against SARS-CoV-2. These products are for use on surfaces, not humans with widely available, and they provide an effective tool against SARS-CoV viruses. Several of these disinfectants are household chemicals, such as alcohols and hypochlorite solutions, are inexpensive, have low toxicity, are easy to use, and have shown excellent biocidal activity within a very short time.

According to data published by the World Health Organization (WHO) and the European Union (EU), the disinfectants that disinfect against COVID-19 are chlorine compounds, alcohols, quaternary ammonium compounds, peroxides, and phenol compounds [13-15]. Ethanol is the most effective chemicals against hydrophilic viruses like coronaviruses. Peroxides target the oxidation of thiol groups and disulfide bonds of proteins and denature them. Aldehydes disinfect them by alkylating their proteins and nucleic acids of coronavirus. Elemental iodine is able to penetrate the membrane and attack proteins at the sulfuryl and disulfide bonds in addition to damaging the nucleic acids [12].

The corona virus (SARS CoV-2 or $\mathrm{nCoV}$ ) that causes COVID-19 is presenting an increasing and urgent need for quarantine and disinfection operations. Potentially contaminated surfaces must be frequently cleaned, to prevent further spread of the virus. The US Environmental Protection Agency (EPA) requires the use of disinfectants that are recognized as being effective in preventing viruses, but this is also increasing the need to solve problems, such as the side effects caused by the increase in disinfectant use [16]. This report examines precautions for the safer use of chemicals handled by workers during quarantine and disinfection in the workplace and proposes policy suggestions.

\section{Principles and preparations of prevention and disinfection}

The legal basis for the disinfection order is Article 47, No. 5 of the IInfectious Diseases Control and Prevention Act」 [17], which orders "the disinfection of places contaminated with infectious disease pathogens or other necessary measures to prevent the spread of infectious diseases"; Article 49, No. 8 of the same Act, "disinfection of facilities or places related to public hygiene"; and No. 13, "disinfection of places contaminated with infectious disease pathogens or ordering other necessary measures," etc.

Accordingly, the Minister of Health and Welfare (MOHW), or the head of local government, etc., notify the supervisor or operator of the contaminated place of the order to conduct disinfection and disinfect the contaminated facility or place at the local public health center. In the case of quarantine, the place, time, etc., are specifically written down and issued to the person in charge of management of 
Table 1 EPA's list of products for use against SARS-CoV-2, the virus that causes COVID-19

\begin{tabular}{|c|c|c|c|}
\hline Chemical name & CAS no. & Inhalation toxicological data & GHS classification of toxicity \\
\hline 1,2-Hexanediol & $6920-22-5$ & - & - \\
\hline Ammonium bicarbonate & $1066-33-7$ & - & - \\
\hline Ammonium carbonate & $10361-29-2$ & - & - \\
\hline Chlorine dioxide & 10049-04-4 & Rat LCLo inhalation $260 \mathrm{ppm} / 2 \mathrm{~h}$ & Acute (inhalation; vapors) category 1 \\
\hline Citric acid & $77-92-9$ & - & - \\
\hline Dodecylbenzenesulfonic acid & $27176-87-8$ & - & - \\
\hline Ethanol (ethyl alcohol) & $64-17-5$ & 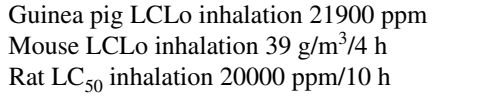 & - \\
\hline Glutaraldehyde & $111-30-8$ & Rat $\mathrm{LC}_{50}$ inhalation $480 \mathrm{mg} / \mathrm{m}^{3} / 4 \mathrm{~h}$ & $\begin{array}{l}\text { Acute (inhalation; vapors) category } 1 \\
\text { Respiratory sensitizer category } 1\end{array}$ \\
\hline Glycolic acid & $79-14-1$ & Rat $\mathrm{LC}_{50}$ inhalation $7.1 \mathrm{mg} / \mathrm{m}^{3} / 4 \mathrm{~h}$ & $\begin{array}{l}\text { Acute (inhalation; dusts/mist) category } 4 \\
\text { Specific target organ toxicity (single exposure) } \\
\quad \text { category 3(respiratory sensitization) }\end{array}$ \\
\hline Hydrochloric acid (Hydrogen chloride) & $7647-01-0$ & $\begin{array}{l}\text { Guinea pig LCLo inhalation } 4413 \mathrm{ppm} / 30 \mathrm{~m} \\
\text { Human LCLo inhalation } 1300 \mathrm{ppm} / 30 \mathrm{~m} \\
\text { Human LCLo inhalation } 3000 \mathrm{ppm} / 5 \mathrm{~m} \\
\text { Mouse LC50 inhalation } 1108 \mathrm{ppm} / 1 \mathrm{~h} \\
\text { Rabbit LCLo inhalation } 4413 \mathrm{ppm} / 30 \mathrm{~m} \\
\text { Rat LC }_{50} \text { inhalation } 3124 \mathrm{ppm} / 1 \mathrm{~h}\end{array}$ & Acute (inhalation; gases) category 3 \\
\hline Hydrogen peroxide & $7722-84-1$ & 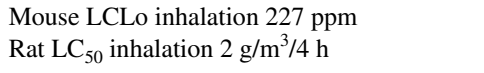 & $\begin{array}{l}\text { Specific target organ toxicity (single exposure) } \\
\text { category 3(respiratory sensitization) }\end{array}$ \\
\hline Hypochlorous acid & $7790-92-3$ & - & - \\
\hline Iodine & $7553-56-2$ & Rat LCLo inhalation $187 \mathrm{ppm} / 1 \mathrm{~h}$ & $\begin{array}{l}\text { Acute (inhalation; dusts/mists) category } 4 \\
\text { Specific target organ toxicity (single exposure) } \\
\text { category 3(respiratory sensitization) }\end{array}$ \\
\hline Isopropanol (Isopropyl Alcohol) & $67-63-0$ & 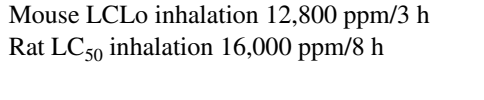 & $\begin{array}{l}\text { Specific target organ toxicity (single exposure) } \\
\text { category 3(narcotic effects) } \\
\text { Aspiration hazard category } 2\end{array}$ \\
\hline L-Lactic acid & $79-33-4$ & - & - \\
\hline Octanoic acid & $124-07-2$ & - & - \\
\hline Peroxyacetic acid (peracetic acid) & $79-21-0$ & Rat $\mathrm{LC}_{50}$ inhalation $450 \mathrm{mg} / \mathrm{m}^{3}$ & Acute (inhalation; vapors) category 1 \\
\hline Peroxyoctanoic acid & $33734-57-5$ & - & - \\
\hline Phenol & $108-95-2$ & $\begin{array}{l}\text { Mouse } \mathrm{LC}_{50} \text { inhalation } 177 \mathrm{mg} / \mathrm{m}^{3} \\
\text { Rat } \mathrm{LC}_{50} \text { inhalation } 316 \mathrm{mg} / \mathrm{m}^{3}\end{array}$ & Acute (inhalation; dusts/mists) category 3 \\
\hline Potassium peroxymonosulfate & $10058-23-8$ & - & - \\
\hline Quaternary ammonium & - & - & - \\
\hline Silver & $7440-22-4$ & - & - \\
\hline Silver ion & $14701-21-4$ & - & - \\
\hline Sodium carbonate & $5968-11-6$ & - & - \\
\hline Sodium carbonate peroxyhydrate & $15630-89-4$ & - & - \\
\hline Sodium chloride & $7647-14-5$ & Rat $\mathrm{LC}_{50}$ inhalation $42 \mathrm{~g} / \mathrm{m}^{3} / 1 \mathrm{~h}$ & - \\
\hline Sodium chlorite & $7758-19-2$ & Rat $\mathrm{LC}_{50}$ inhalation $230 \mathrm{mg} / \mathrm{m}^{3} / 4 \mathrm{~h}$ & Acute (inhalation; dusts/mists) category 2 \\
\hline Sodium dichloroisocyanurate & 2893-78-9 & - & - \\
\hline Sodium dichloroisocyanurate dihydrate & $51580-86-0$ & - & - \\
\hline Sodium hypochlorite & $7681-52-9$ & - & - \\
\hline Tetraacetylethylenediamine & $10543-57-4$ & - & - \\
\hline Thymol & $89-83-8$ & - & - \\
\hline Triethylene glycol & $112-27-6$ & - & - \\
\hline
\end{tabular}

*Sourced from “EPA (2020) Pesticide Registration, List N: Disinfectants for Use Against SARS-CoV-2.” [12] https://www.epa.gov/pesticideregistration/list-n-disinfectants-use-against-sars-cov-2-covid-19. See also "List N Tool: COVID-19 Disinfectants", https://cfpub.epa.gov/giwiz/ disinfectants/index.cfm

The inhalation toxicology data was sourced by ChemIDplus Advanced, U.S. National Library of Medicine. https://chem.nlm.nih.gov/chemidplus 
the disinfection facility $[11,18,19]$. The manager of the facility receiving the disinfection order shall follow the method of disinfection of 「Attachment 6$\lrcorner$ in the Enforcement Regulation of the Infectious Disease Prevention Act $[20,21]$. The above contents are introduced in detail in the IInformation on Disinfection of Group Facilities and Multi-Use Facilities (3-2 Edition)」 announced by the MoE [22].

Even if the disinfectant meets the safety standards, if the instructions for its use are not followed correctly, it may be harmful to the health of workers. Therefore, before use, it is necessary to properly understand the method of use, precautions, and first-aid measures prescribed for the disinfectant product. Household disinfectants, namely "YuHanClo Rox $^{\circledR}$ " or just "Rox ${ }^{\circledR}$ " (brand names in Korea), generally contain about $5 \%$ sodium hypochlorite, so pour $10 \mathrm{~mL}$ of undiluted solution into $500 \mathrm{~mL}$ or more of cold water and mix to make $0.1 \%$ (1000 ppm) disinfectant solution that exerts a disinfection effect (Table 2). At this time, it must be diluted immediately before use in a well-ventilated place, and it is recommended to use protective equipment, such as disposable gloves and a health mask (KF94 equivalent). Disinfection in workplaces and in the everyday environment is to quarantine and disinfect all surfaces that workers make frequent contact with, such as computer keyboards, telephones, handrails, and handles. If the surface is dirty, before disinfection, it should be cleaned with detergent or soap and water. As far as possible, workers should avoid using other workers' telephones, desks, offices, or other work tools and equipments; if necessary, these must be cleaned and disinfected before and after use. Disposable cleaning tools (cloth) must be provided to wipe commonly used surfaces (door handles, keyboards, remote controls, desks, other work tools

Table 2 Dilution ratio of sodium hypochlorite disinfectant

\begin{tabular}{|c|c|c|c|}
\hline \multirow{2}{*}{$\begin{array}{l}\text { Effective chlo- } \\
\text { rine concentra- } \\
\text { tion against the } \\
\text { virus }(\mathrm{ppm})\end{array}$} & \multirow{2}{*}{$\begin{array}{l}\text { Sodium } \\
\text { hypochlorite } \\
\text { final concentra- } \\
\text { tion }(\%)\end{array}$} & \multicolumn{2}{|c|}{$\begin{array}{l}\text { Sodium hypochlorite: water } \\
\text { mixing ratio }\end{array}$} \\
\hline & & $\begin{array}{l}4 \% \\
(40,000 \mathrm{ppm}) \\
\text { undiluted solu- } \\
\text { tion }\end{array}$ & $\begin{array}{l}5 \% \\
(50,000 \mathrm{ppm}) \\
\text { undiluted } \\
\text { solution }\end{array}$ \\
\hline 500 & 0.05 & $1: 80$ & $1: 100$ \\
\hline 1000 & 0.1 & $1: 40$ & $1: 50$ \\
\hline 5000 & 0.5 & $1: 8$ & $1: 10$ \\
\hline 10,000 & 1.0 & $1: 4$ & $1: 5$ \\
\hline
\end{tabular}

Dilution ratio and chlorine concentration according to the effective chlorine concentration of the commercially available sodium hypochlorite disinfectant stock solution

*Sourced from "COVID-19 sterilization, detailed guidelines for the safe use of disinfection products" (5/11/20) [8]. See also "Cleaning and disinfection of environmental surfaces in the context of COVID19", https://www.who.int/publications/i/item/cleaning-and-disinfecti on-of-environmental-surfaces-inthe-context-of-covid-19 and equipments, etc.), and disinfectants that are approved for coronavirus by the MoE, and by the WHO, ECDC, etc. For disinfectant, products approved and declared by the MoE are used, and the usage, dosage, and precautions for each product must be observed. Information on the list of disinfectants can be found at Green Nuri (http://ecolife.me.go.kr) of the MoE [23].

In the case of the bathroom, a high sodium hypochlorite diluted solution of $1000 \mathrm{ppm}$ should be used to clean the surface of the bathroom, including the toilet. Disinfectants, such as chlorine, can damage the surface, and after the indicated contact time has passed, should be wiped with disposable wipes, etc. Disinfectants prepared by diluting the undiluted solution must indicate the expiration date, and waste produced during cleaning must be placed in a separate waste bag, closed tightly, and placed in a mixed waste container for immediate disposal [24]. The challenge is to effectively transfer the scientifically sound knowledge, appropriate tools, and effective methodologies to employers and workers, through the coordination of different scientific associations [25].

\section{Safety and health measures for quarantine and disinfection workers}

The disinfectants used for COVID-19 are those approved by the MoE, or recommended by the WHO, CDC, etc., and it is desirable to use an environment-friendly disinfectant, which is a product approved and reported by the MoE. However, if there is no environment-friendly disinfectant available, alcohol diluted to $70 \%$ can be used [22]. Alcohol is a water-soluble organic compound, composed of a high concentration of ethanol and isopropanol (isopropyl alcohol), and has an antibacterial effect. Ethanol at a concentration of (60-80)\% has strong antiviral action against hydrophobic (lipophilic) viruses (e.g., herpes, vaccinia, and influenza viruses) and hydrophilic viruses (e.g., adenovirus, enterovirus, rhinovirus, and rotavirus). Isopropanol also has antiviral activity against lipid viruses, and when diluted to (60-80)\% in water, becomes an effective disinfectant.

In the case of household disinfectant, namely "YuHanClo Rox ${ }^{\circledR}, "$ it is readily available, and the WHO and the CDC have proven its disinfectant effect [8]. When cleaning the surface with a disinfectant-soaked disposable cloth or rag, make sure that the surface comes into contact with the disinfectant for at least 10 min to take effect; after the disinfectant dries, wipe the surface several times with a water-soaked disposable cloth. Disinfection of textile products by washing with hot water mixed with a hot detergent or disinfectant is good, and steam disinfection is possible for those articles that are difficult to wash. Incidentally, there was a case in 2019 of a workplace industrial accident in which the reaction 
of a mixture of disinfectant chemicals released toxic gases, which resulted in a worker's death. This incident occurred when the operator used a different type of cleaning product to clean a floor where the initial spill of cleaning chemicals remained. Rachael Rettner reported an example of a workplace accident in 2019 caused by a mixture of incompatible chemicals [26], in which in a famous chain restaurant, reactions between common but incompatible cleaning chemicals released toxic gases, which resulted in the worker's death. There was an incident in a chain store. An employee at Buffalo Wild Wings, a restaurant in Burlington, Massachusetts, USA, died after exposure to toxic fumes from general cleaning products, and more than a dozen people were injured from toxic fumes. This occurred when the employee started cleaning the floor with a commercially available cleaner called Super 8 containing sodium hypochlorite, and another acid-containing cleaner called "Scale Kleen" was spilt onto the floor, and the residue of the cleaning liquid was coated on the floor. The mixture of the two chemicals turned green and created a foamy substance and caused the staff burning eyes or symptoms of difficulty in breathing. The worker later died in hospital, and another 13 were reportedly exposed to the smoke. Incorrect mixing of cleaning and disinfecting products can be fatal, and chlorine-based bleach can react with ammonia, acids, and other detergents [26].

As quarantine and disinfection increase due to COVID19 , the possibility of unsafe use of chemicals increases, such as mixing and using chemicals that should not be mixed, due to a lack of understanding of each chemical. For example, quaternary ammonium compounds (Maquat 128 PD) are chemicals widely used as surfactants and disinfectants, but they act as strong bases in acid-base reactions and react with strong oxidizing agents. Therefore, there is the possibility that both active ingredients, such as hydrogen peroxide (oxidant) and peracetic acid (Cosa Oxonia Active), react with quaternary ammonium compounds. In addition, quaternary ammonium compounds can react strongly with chlorine to release toxic gases. As many common quarantine measures include bleach and disinfection products contain chlorine, care should be taken. The reaction and strength due to compound mixing may vary depending on the concentration and composition of the mixture, so material safety data sheets (MSDS) must be provided to workers for the safer use of chemical substances, and in particular, they must be provided with material safety and health data describing handling and storage methods. The chemical should only be used after training to familiarize the worker with the information in "As conclusions, future works for quarantine workers in response to COVID-19" section of the MSDS [27].

Bleach or sodium hypochlorite should not be mixed with acids, ammonia, or hydrogen peroxide. As an example, vinegar is an aqueous solution of acetic acid and should not be mixed with bleach; when mixed, it can create toxic chlorine gas and create a dangerous situation. Group facility and multi-use facility disinfection instructions should state that different disinfectants should not be mixed, and disinfectant should not be put close to flammable chemicals and should only be used in well-ventilated areas. It is also recommended that sodium hypochlorite should never be mixed with other disinfectants.

\section{The importance of using protective equipment}

When cleaning areas where people infected with COVID-19 have stayed or have been in contact, an additional impermeable long-sleeved protective suit and apron must be worn over the clothing. During cleaning, protective gloves (e.g., nitrile rubber gloves with a minimum thickness of $0.3 \mathrm{~mm}$ complying with EN 374-1 standard) should be used, and the employer must supply appropriate protective gloves with the correct specifications. If necessary, double gloves can be used, with a thin disposable inner layer and a chemical resistant outer layer [27]. When using chlorine-based disinfectants, respiratory protection should be worn, the protective equipment should be disinfected after cleaning, care should be taken when removing protective equipment to avoid contact with its outer surface, and after removing gloves and other personal protective equipment (PPE), they should be washed in warm water and soap or alcohol to remove disinfectant ingredients. If they cannot be washed with soap, an alcohol-based disinfectant should be used and hand washed as often as possible [14].

For industrial hygiene management, it is important to thoroughly understand the MSDS. Section 8 of MSDS contains information on exposure controls and personal protection, as well as information on adequate ventilation, other engineering measures, and appropriate PPE. Because of COVID-19, many workplaces now use chemicals that have not been used before for disinfection and quarantine; even if they have used a much larger amount of chemicals, it is necessary and very important to know the MSDS contents in advance before safe work.

The risk of COVID-19 among healthcare workers compared with the general community and the effect of PPE were assessed. Healthcare systems should ensure the availability of PPE and adequate strategies to protect workers from COVID-19 virus [28]. Since the main mode of spread in the community is transmission through infected respiratory droplets from patients with symptoms and asymptomatic carriers, there is no standard to treat the disease, or at present, any effective vaccine. Therefore, social distancing and hand washing were introduced to slow down the progression of the pandemic. Universal masking as a public 
Table 3 Preventive precautions for the use of chemicals with disinfection

Precautions for quarantine work

(1) When quarantining and disinfecting, the cleaning worker should be informed that the chemical must not come into contact with the face, especially the mouth, nose, and eyes; the cleaning worker should wear impervious disposable gloves and masks, and face and eye protection

(2) When touching tools for quarantine and disinfection, rubbing alcohol on your hands before and after wearing gloves

(3) Before and after removing the mask and eye protection, hands should be disinfected with an alcohol-based disinfectant

(4) If contaminated hands and fingers inadvertently touch the face, masks and eye protection, whether wearing gloves or not, act as a last barrier

(5) Prevention of respiratory secretions or other body fluids with visible contamination. In addition to masks, eye protection and gloves, disinfection workers must wear a full-length disposable gown

(6) Consult the workplace safety and health manager for advice on the correct procedure for wearing personal protective equipment (PPE)
Precautions when using disinfectant

(1) When using newly made properly diluted bleach, follow the manufacturer's instructions

(2) Use a disposable paper towel or disposable cloth to wipe the area with bleach

(3) Gloves and masks should be disposed of in leak-proof plastic bags

(4) Wash hands with soap for at least $30 \mathrm{~s}$ and dry them with disposable paper or disposable cloth

(5) If hands cannot be washed with water, rub hands with alcohol

(6) Gloves should be worn when handling and preparing the bleach solution, and in the case of splashing, safety goggles should be worn

(7) Bleach solution is prepared on a daily basis and is primarily used on hard, non-porous surfaces (which can damage fabrics and metals)

(8) Sufficient time is required to kill the virus (e.g., at least $10 \mathrm{~min}$ ), bleach has various advantages, and the concentration of the active ingredient and hypochlorous acid should be confirmed in the product manual

*Sourced from "Central Defense Countermeasure Headquarters. Central Accident Control Center. Group facilities for patients with coronavirus infection-19. Guide to Disinfection of Multi-Use Facilities" [11]

health intervention is currently mandatory to avoid a PPE shortage crisis [29]. In order to reduce the potential transmission of the virus, these measures should help to decrease the risk of the infection and represent an aggravating factor to counteract the heat effects at occupational and environmental conditions [30]. Risks due to chemical substances in quarantine and disinfection work are different from those for workers in direct contact with people with infectious diseases, and Table 3 shows the precautions.

\section{As conclusions, future works for quarantine workers in response to COVID-19}

In order to safely and effectively use the chemical products used in the prevention and disinfection of COVID-19, the manufacturer's instructions, such as adequate ventilation, must be read and followed, and the expiration date of the product must also be checked. Diluted household bleach could also be used, but it is also important not to mix with ammonia or other disinfectants.

As the pandemic reaches low-income countries, it puts healthcare workers at high risk and challenges the abilities of healthcare systems to respond to the crisis. Furthermore, effective educational training programs should be implemented to ensure the maintenance of appropriate practices during the pandemic. In particular, workers who perform cleaning, laundry, and garbage collection should be educated to recognize the symptoms of COVID-19, and workers protection policies should be established, such as providing guidance on actions to be taken by workers when symptoms appear within 14 days of exposure to the virus. For all cleaning workers, the practices of when to use PPE, how to wear and take it off, how to dispose of it, and the quarantine used in the workplace should all be according to the Occupational Safety and Health Act. It is necessary to educate workers about the dangers and hazards of disinfecting chemicals, etc. It is also necessary to guide cleaning workers to comply with national and international standards and rules for the proper disposal of regulated waste.

The COVID-19 pandemic will have long-lasting effects on workers, especially related to their health issues, financial hardship, and inability to enjoy future employment opportunities. During a pandemic, syndromic methods for monitoring illness outside of healthcare settings, such as tracking absenteeism trends in workplaces, can be useful adjuncts to conventional disease reporting. In particular, workers who perform cleaning, laundry, and garbage collection should be educated to recognize the symptoms of COVID-19, and protection policies, such as providing guidance on actions, should be implemented. It is also necessary to guide cleaning workers to comply with national and international standards (legislation, etc.) for the proper disposal of regulated waste.

Acknowledgements This study was supported by the Korean Occupational Safety and Health Agency (Ulsan, Republic of Korea), the Ministry of Employment and Labor (Sejong, Republic of Korea), and a Grant-in-Aid for chemical hazard evaluation (2020).

\section{Compliance with ethical standards}

Conflict of interest Kyung-Taek Rim declares that he has no conflict of interest. 
Ethical approval This article does not contain any studies with human participants or animals performed by any of the authors.

\section{References}

1. Australian Government (2020) Department of Health. Environmental cleaning and disinfection principles for COVID19. https ://www.health.gov.au/sites/default/files/documents/2020/03/envir onmental-cleaning-and-disinfection-principles-for-covid-19.pdf

2. Health Consumer (2020) http://www.healthumer.com. (in Korean)

3. Alderman C (2020) COViD-19: face mask effectiveness, hand sanitizer shortages, and rapid medication therapy trials. Sr Care Pharm 35:243-246. https://doi.org/10.4140/TCP.n.2020.243

4. Bong CL, Brasher C, Chikumba E, McDougall R, Mellin-Olsen J, Enright A (2020) The COVID-19 pandemic: effects on low- and middle-income countries. Anesth Analg 131:86-92. https://doi. org/10.1213/ANE.0000000000004846

5. Flocks J (2020) The potential impact of COVID-19 on H-2A agricultural workers. J Agromed. https://doi.org/10.1080/10599 24X.2020.1814922

6. Garzillo EM, Monaco MGL, Spacone A, Inglese E, Lamberti M, Pompei D (2020) SARS-CoV-2 emergency in the workplace: are companies ready to protect their workers? A cross-sectional survey. Int J Occup Saf Ergon. https://doi.org/10.1080/10803 548.2020 .1810457

7. KBS News (2020) COVID-19 pandemic. http://news.kbs.co.kr/ news/view.do?ncd $=4424725$. (in Korean)

8. Centers for Diseases Control and Prevention (2008) Guideline for disinfection and sterilization in healthcare facilities. https:// www.cdc.gov/infectioncontrol/pdf/guidelines/disinfection-guide lines-H.pdf. (in Korean)

9. National Environment Agency in Singapore (2020) Interim guidelines for environmental cleaning and disinfection of areas exposed to confirmed case(s) of 2019 novel coronavirus (2019-nCoV) in non-healthcare commercial premises. https:/www.nea.gov.sg/ our-services/public-cleanlines/environmental-cleaning-guidelines /guidelines/guidelines-for-environmental-cleaning-and-disinfecti on

10. Yildirim TT, Atas O, Asafov A, Yildirim K, Balibey H (2020) Psychological status of healthcare workers during the Covid19 pandemic. J Coll Phys Surg Pak 30:26-31. https://doi. org/10.29271/jcpsp.2020.Supp1.S26

11. Ministry of Environment Korea (2020) Guide to disinfection of community facility and multi-use facilities. 3-4 edn. http:// ncov.mohw.go.kr/upload/viewer/skin/doc.html?fn=1597838974 522_20200819210935.hwp\&rs=/upload/viewer/result/202009/

12. Al-Sayah MH (2020) Chemical disinfectants of COVID-19: an overview. J Water Health 18:843-848. https://doi.org/10.2166/ wh. 2020.108

13. WHO, UICEF (2020) Water, sanitation, hygiene, and waste management for SARS-CoV-2, the virus that causes COVID-19 Interim guidance, COVID-19: infection prevention and control/ WASH. https://www.who.int/publications/i/item/water-sanitation -hygiene-and-waste-management-for-the-covid-19-virus-interimguidance

14. World Health Organization (2018) How to put on and take of personal protective equipment. https://www.who.int/csr/resources/ publications/PE_EN_A1sl.pdf

15. World Health Organization (2020) Infection prevention and control during health care when novel coronavirus (nCoV) infection is suspected. Interim guidance, COVID-19: infection prevention and control/WASH. https://www.who.int/publications/i/item/infec tion-prevention-and-control-during-health-care-when-novel-coron avirus-(ncov)-infection-is-suspected-20200125

16. EPA (2020) Pesticide registration, list N: disinfectants for use against SARS-CoV-2. https://www.epa.gov/pesticide-registration/ list-n-disinfectants-use-against-sars-cov-2-covid-19

17. KCDC (2020) Infectious disease control and prevention act. https://elaw.klri.re.kr/eng_mobile/ganadaDetail.do?hseq=37239 $\&$ type $=$ abc $\&$ key $=$ INFEC TIOUS $\% 20$ DIS EASE $\% 20 \mathrm{CON}$ TROL\%20AND\%20PREVENTION\%20ACT\&param=I

18. Ministry of Health Singapore (2014) MOH pandemic readines and response plan for influenza and other acute respiratory diseases. https://www.moh.gov.sg/docs/librariesprovider5/diseases-updates/ interim-pandemic-plan-public-ver-_april-2014.pdf?sfvrsn=95ac7 ac3_0

19. Australian Government (2020) Department of Health. Local state and territory health department. https://www.health.gov.au/about -us/contact-us/local-state-and-territory-health-departments

20. KCDC (2020) Enforcement regulations of the infectious disease control and prevention act [attachment 6] methods of disinfection. https://elaw.klri.re.kr/eng_mobile/ganadaDetail.do?hseq=37239 $\&$ type $=$ abc $\&$ key $=$ INFECTIOUS $\% 20$ DIS EASE $\% 20 \mathrm{CON}$ TROL\%20AND\%20PREVENTION\%20ACT\&param=I

21. KCDC (2020) Article 47 and 49. The infectious disease control and prevention act. https://elaw.klri.re.kr/eng_mobile/ganad aDetail.do?hseq $=37239 \&$ type $=$ abc $\&$ key $=$ INFECTIOUS $\% 20$ DIS EASE\%20CONTROL\%20AND\%20PREVENTION\%20ACT \&param $=\mathrm{I}$

22. Ministry of Environment Korea (2020) Safety control act of household chemical products and biocidal products (K-BPR). https://msc.ul.com/en/resources/article/south-korea-enacts-thesafety-control-act-of-household-chemical-products-and-bioci dal-products-k-bpr/

23. Ministry of Environment Korea (2020) Request for compliance with precautions such as use and usage for disinfection and quarantine related to COVID-19. The document of the Ministry of Environment (Chemical Product Management Division-338, 25 February 2020). (in Korean)

24. Health Chosun (2020) http://health.chosun.com/site/data/html_ dir/2020/03/23/2020032304352.html. (in Korean)

25. Spinazzè A, Cattaneo A, Cavallo DM (2020) COVID-19 outbreak in Italy: protecting worker health and the response of the italian industrial hygienists association. Ann Work Expo Health 64:559564. https://doi.org/10.1093/annweh/wxaa044

26. Rettner R (2019) 2 everyday chemicals created toxic fumes that killed buffalo wild wings manager: workers were exposed to toxic fumes created by a mix of bleach and acid, according to news reports. https://www.livescience.com/buffalo-wild-wings-death -cleaner-fumes.html

27. US Department of Labor, OSHA (2020) 3990-03 2020, Guidance on preparing workplaces for COVID19. https://www.osha.gov/ Publications/OSHA3990.pdf

28. Nguyen LH, Drew DA, Graham MS, Joshi AD, Guo CG et al (2020) Coronavirus pandemic epidemiology consortium. Risk of COVID-19 among front-line health-care workers and the general community: a prospective cohort study. Lancet Public Health 5:e475-e483. https://doi.org/10.1016/S2468-2667(20)30164-X

29. Beesoon S, Behary N, Perwuelz A (2020) Universal masking during COVID-19 pandemic: can textile engineering help public health? Narrative review of the evidence. Prev Med 139:106236. https://doi.org/10.1016/j.ypmed.2020.106236

30. Morabito M, Messeri A, Crisci A, Pratali L, Bonafede M, Marinaccio A, WORKLIMATE Collaborative Group (2020) Heat warning and public and workers' health at the time of COVID-19 pandemic. Sci Total Environ 738:140347. https://doi. org/10.1016/j.scitotenv.2020.140347 